\title{
HUBUNGAN ANTARA RESILIENSI DAN PENERIMAAN ORANGTUA PADA IBU DARI ANAK YANG TERDIAGNOSIS AUTISM SPECTRUM DISORDER (ASD)
}

\author{
Stefany Valentia ${ }^{1}$, \\ Riryn Sani, \\ Yuliana Anggreany \\ Fakultas Psikologi \\ Universitas Pelita Harapan \\ J1. MH. Thamrin Boulevard, Lippo Karawaci \\ Tangerang 15811, Indonesia \\ 'e-mail: stefany.valentia@gmail.com
}

\begin{abstract}
This study aims to examine the relationship between resilience and parental acceptance of mothers of children diagnosed with Autism Spectrum Disorder (ASD). The sample consisted of 51 mothers. Brief Resilience Scale (BRS) and Parental AcceptanceRejection Questionnaire (PARQ) were used to assess mother's resilience and parental acceptance level. The results indicated a significantly negative correlation between resilience and parental acceptance $(r=-.330, p<.05)$. Furthermore, this study also found significant correlations between some of the parental acceptance dimensions and resilience level.
\end{abstract}

Keywords: resilience; parental acceptance; mother of children with Autism Spectrum Disorder.

Abstrak - Penelitian ini bertujuan untuk menguji secara empiris hubungan antara resiliensi dan penerimaan orangtua pada ibu dari anak yang terdiagnosis Autism Spectrum Disorder (ASD). Partisipan terdiri atas 51 orang ibu yang mengisi Brief Resilience Scale (BRS) sebagai instrumen pengukur resiliensi, dan Parental Acceptance-Rejection Questionnaire (PARQ) sebagai instrumen pengukur penerimaan orangtua. Hasil pengolahan data menunjukkan adanya hubungan signifikan yang berbanding terbalik antara variabel resiliensi dengan skor alat ukur penerimaan orangtua $(r=-.330, p<.05)$. Penemuan lain yang terkait dengan hubungan antara dimensi resiliensi dan penerimaan orangtua juga turut didiskusikan.

Kata Kunci: resiliensi; penerimaan orangtua; Autism Spectrum Disorder. 


\section{PENDAHULUAN}

Salah satu gangguan perkembangan yang makin meningkat di kalangan masyarakat Indonesia adalah Autism Spectrum Disorder (Danuatmaja, 2003). Autism Spectrum Disorder (ASD) adalah gangguan perkembangan yang ditandai dengan kesulitan dalam melakukan komunikasi verbal maupun non-verbal dan interaksi sosial (American Psychiatric Association [APA], 2013). Menurut DSM-V, individu dengan ASD harus menunjukkan gejala-gejala dalam kriteria yang terdapat pada DSM sejak awal masa kanak-kanak. Gangguan ini menggunakan kata spectrum yang mengartikan bahwa jangkauan area yang mengalami gangguan sangat beragam antar individu (Mash \& Wolfe, 2013). Di Indonesia sendiri belum terdapat data statistik yang resmi mengenai prevalensi ASD dari badan pemerintahan. Namun, berdasarkan data dari Badan Pusat Statistik (BPS), diperkirakan sejak 2010 hingga 2016 terdapat sekitar 140 ribu anak di bawah usia 17 tahun yang menyandang ASD. Pada awal tahun 2000 prevalensi ASD adalah sekitar 1:1000 kelahiran, namun penelitian pada tahun 2008 menunjukkan peningkatan hingga 1.68:1000 kelahiran (Nelwansyah, dalam Kurnia, 2015).

Setiap orangtua pasti berharap anak mereka dapat bertumbuh dengan baik. Namun ketika anak terdiagnosis memiliki gangguan tertentu, orangtua juga mengalami dampaknya. Tantangan yang dihadapi berkaitan dengan ASD tidak hanya dialami oleh individu yang terdiagnosis, namun juga dihadapi oleh orang-orang yang merawatnya, terutama orangtua, saudara, guru, tenaga ahli, dan komunitas lingkungannya (Mandell, 2012).

Kondisi ASD dapat dikatakan berbeda dari gangguan-gangguan lain, dan karakteristik anak dengan gangguan ASD dapat menjadi sumber stres tambahan bagi orangtua, serta menjadi sumber masalah bagi keluarga (Autism Europe, 2001). Secara khusus, karakteristik anak dengan ASD berbeda dengan gangguan perkembangan lainnya, terutama dalam masalah membina hubungan interpersonal. Anak-anak dengan ASD kurang dapat merespon orang lain di sekitarnya dan kurang memiliki minat untuk berinteraksi dengan orang lain. Hal ini dapat terlihat sejak bayi, di mana mereka kurang mampu membentuk ikatan emosional yang wajar dengan pengasuh utama mereka. Mereka jarang menoleh ketika dipanggil dan jarang melakukan kontak mata ketika diajak berbicara. Selain itu, mereka juga menunjukkan perilaku menghindar atau mengabaikan ketika disayang, dipeluk, dicium, atau dielus oleh orangtua mereka (Safaria, 2005). 
Anak-anak dengan ASD juga seringkali memiliki minat yang terbatas dan melakukan suatu hal secara berulang-ulang. Mereka tidak suka terhadap perubahan pada rutinitas sehari-hari, sehingga hal ini memengaruhi fungsi adaptif mereka. Mereka mengalami kesulitan ketika harus beradaptasi dengan lingkungan yang baru (Mash \& Wolfe, 2013). Kesulitan lain yang dihadapi orangtua dari anak dengan ASD antara lain komunikasi yang buruk, penolakan dan kurangnya pengertian dari lingkungan sosial, kesulitan dalam menghadapi perilaku anak, pertengkaran antar pasangan suami istri, dan masalah finansial (Papageorgiou \& Kalyva, 2010). Karakteristik-karakteristik yang terdapat dalam diri anak dengan ASD ini bersifat jangka panjang, bahkan terus menetap seumur hidup mereka, sehingga hal ini menjadi tantangan terbesar orangtua dari anak dengan ASD (Greeff \& Van der Walt, 2010).

Terdapat beberapa orangtua yang mampu menghadapi tantangan-tantangan terkait dengan mengurus anak dengan ASD, namun tidak demikian bagi sebagian lainnya (Greeff \& Van der Walt, 2010). Resiliensi merupakan salah satu faktor yang dapat membantu keluarga dalam menyesuaikan diri dan menghadapi permasalahan yang mereka alami, terkait dengan anak yang terdiagnosis ASD di dalam keluarga. Resiliensi sendiri diartikan sebagai kemampuan individu untuk bangkit kembali dalam situasi yang menekan (Smith, dan kawan-kawan., 2008).

Resiliensi menjadi hal yang sangat penting untuk dimiliki oleh orangtua, karena resiliensi bukan sekedar membantu orangtua menghadapi tantangan tetapi juga memampukan orangtua untuk bangkit kembali dalam situasi menekan yang bersifat jangka panjang ini. Hal ini didukung pula oleh Lyons, Parker, Katz, dan Schatzberg (2009) yang menyampaikan salah satu manfaat utama dari resiliensi, yaitu adanya efek penguatan, di mana resiliensi akan mengurangi kerentanan individu terhadap stres, meskipun dipaparkan pada stressor dan kesulitan yang terus-menerus.

Selain bagi orangtua sendiri, resiliensi yang dimiliki orangtua juga akan berdampak positif bagi perkembangan anak yang memiliki gangguan ASD tersebut. Orangtua yang resilien dapat tetap tangguh, berkomitmen untuk membantu anak mereka yang memiliki gangguan ASD, serta menjadikan anak mereka sebagai prioritas utama, yang pada akhirnya akan meningkatkan kemampuan keluarga untuk dapat beradaptasi lebih baik dengan situasi yang mereka hadapi tersebut (Walsh, 2003). Sedangkan orangtua yang kurang resilien cenderung menjadi tidak peduli dengan kondisi anaknya, menelantarkan anaknya, atau menyerahkan tanggung jawab pengasuhan kepada orang lain (Cunningham \& Boyle, 2002). Tanpa resiliensi, orangtua kemungkinan besar tidak dapat meresponi situasi yang menimbulkan stres dengan efektif (Taylor, 2012). 
Selain resiliensi, hal lain yang dapat memengaruhi keberhasilan orangtua dalam menghadapi tantangan terkait anak dengan gangguan ASD yaitu penerimaan mereka terhadap sang anak (Kandel \& Merrick, 2007). Penerimaan orangtua terhadap anak diartikan oleh Rohner (1986) sebagai perilaku pengasuhan orangtua yang ditandai dengan kehangatan, kasih sayang, perawatan, kenyamanan, perhatian, pemeliharaan, dukungan, dan cinta kepada seorang anak. Rohner juga mengemukakan bahwa di sisi kutub yang lain dari penerimaan orangtua, terdapat dimensi penolakan orangtua, yaitu perilaku pengasuhan orangtua yang ditandai dengan tidak adanya kehangatan serta perilaku menyakitkan yang ditujukan pada anak, baik dalam bentuk fisik maupun psikologis. Dalam konteks ini, tentu yang diharapkan adalah adanya penerimaan orangtua pada anak.

Penerimaan orangtua menjadi hal yang penting karena akan memengaruhi bagaimana perkembangan anak dengan gangguan ASD di kemudian hari. Ketika orangtua sudah dapat menerima anak, orangtua akan lebih berusaha dalam mengerti gangguan yang dimiliki anak dan berusaha memberikan fasilitas atau penanganan yang dibutuhkan oleh anak (Dunst \& Trivette, 1986). Sementara itu, orangtua yang tidak dapat menerima gangguan yang dimiliki anaknya akan mengalami kesulitan untuk merespons anak dengan tepat dan kurang mampu membangun relasi yang kuat dengan sang anak (Barnett, Clements, Kaplan-Estrin, \& Fialka, 2003).

Penelitian-penelitian terdahulu lebih banyak berfokus pada area negatif, seperti misalnya masalah disfungsi keluarga dengan anak yang memiliki gangguan perkembangan mental maupun fisik, sedangkan fungsi adaptif keluarga dengan anak yang memiliki gangguan perkembangan mental belum terlalu banyak mendapatkan perhatian (Rathore \& Mathur, 2014). Sedangkan dari penjelasan yang telah dipaparkan sebelumnya, dapat dilihat bahwa variabel penerimaan orangtua dan resiliensi sama-sama dapat membantu perkembangan anak yang memiliki gangguan ASD sekaligus memberikan dampak positif bagi orangtua sendiri. Oleh karena itu, peneliti berminat untuk meneliti hubungan kedua variabel tersebut lebih lanjut. Adapun penelitian ini difokuskan kepada ibu karena sebagai orangtua, ibu adalah sosok yang lebih berperan sebagai pengasuh utama bagi anak-anak dan menghabiskan waktu lebih banyak dengan anak mereka (Llyod \& Hastings, 2009).

\section{Resiliensi}

Belum ada definisi resiliensi yang menjadi kesepakatan bersama (Herrman, dan kawan-kawan., 2011), tetapi resiliensi dalam penelitian ini didefinisikan sebagai kemampuan individu untuk dapat bangkit kembali dalam situasi yang menekan (Smith, dan kawan-kawan., 2008). Faktor-faktor yang 
mempengaruhi resiliensi antara lain self-efficacy (Connor \& Davidson, 2003), kendali kognitif dan emosi, adaptability (Connor \& Davidson, 2003; Reivich \& Shatte, 2002), agama dan spiritualitas (Connor \& Davidson, 2003; Masten, 2001), status sosial ekonomi (Masten, 2001), dan dukungan sosial (Wolkow \& Ferguson, 2001).

\section{Penerimaan Orangtua}

Penerimaan orangtua didefinisikan sebagai perilaku pengasuhan orangtua yang penuh kehangatan dan kasih sayang (Rohner, 1986). Menurut Rohner, pengasuhan orangtua membentuk suatu kontinum di mana setiap manusia dapat ditempatkan di posisi tertentu. Salah satu sisi dari kontinum merupakan penerimaan orangtua, sedangkan sisi lain dari kontinum tersebut adalah penolakan orangtua, yaitu perilaku pengasuhan orangtua yang ditandai dengan dengan tidak adanya kehangatan serta perilaku menyakitkan yang ditujukan pada anak, baik dalam bentuk fisik maupun psikologis. Pengasuhan rutin kepada anak tidak secara otomatis menunjukkan penerimaan orangtua terhadap anak, sebab orangtua yang menerima akan menunjukkan kehangatan dan afeksi dan bukan sekedar perasaan tanggung jawab terhadap anak.

Rohner (1986) membagi penolakan orangtua dalam berbagai kombinasi perilaku, yaitu cold and unaffectionate, berupa ketiadaan kehangatan dan afeksi; hostile and aggressive, berupa perilaku menyakiti secara verbal dan fisik; indifferent and neglect, berupa perilaku mengabaikan anak; serta undifferentiated rejecting, berupa kondisi di mana orangtua menunjukkan penolakan terhadap anak, namun bentuk penolakan tersebut tidak dapat dikategorikan dalam tiga kategori lain.

\section{METODE}

\section{Partisipan}

Partisipan dalam penelitian ini adalah 51 orang ibu yang memiliki anak dengan gangguan ASD, berdomisili di daerah Jabodetabek, serta diagnosis anak diberikan oleh profesional. Ibu yang dapat menjadi partisipan penelitian ini adalah ibu dari anak yang memiliki gangguan ASD, baik ibu kandung maupun ibu tiri, sedangkan diagnosis dapat didasarkan pada Panduan Penegakan Diagnosis Gangguan Jiwa (PPDGJ), DSM-IV-TR, atau DSM-V. Penelitian ini menggunakan teknik non-probability sampling dalam pengambilan datanya, dengan jenis purposive sampling karena sudah ada kriteria sampel yang spesifik. 


\section{Desain}

Penelitian ini menggunakan pendekatan kuantitatif dengan metode survei untuk mengukur variabel resiliensi dan penerimaan orangtua.

\section{Prosedur}

Alat ukur yang digunakan adalah Brief Resilience Scale (Smith, dan kawan-kawan., 2008) untuk mengukur resiliensi, dan Parental Acceptance-Rejection Questionnaire (PARQ Parent: Mother Version) yang dikembangkan oleh Rohner (2005) untuk mengukur penerimaan orangtua. Brief Resilience Scale (Smith, dan kawan-kawan., 2008) memiliki 6 butir, dan hasil adaptasi alat ukur menghasilkan nilai Cronbach's Alpha sebesar.601, dan corrected item-total correlation sebesar.206-.462 (Puteri, 2014). Sementara itu, Parental Acceptance-Rejection Questionnaire (Rohner, 2005) memiliki 24 butir dan hasil adaptasi alat ukur yang dilakukan peneliti menghasilkan nilai Cronbach's Alpha sebesar.834, dan corrected item-total correlation sebesar.193-.628.

Peneliti menghubungi beberapa kerabat pribadi yang memenuhi kriteria untuk menjadi sampel dalam penelitian ini, serta berkunjung ke beberapa Sekolah Luar Biasa (SLB) dan pusat terapi anak berkebutuhan khusus di daerah Jakarta dan sekitarnya. Pengambilan data menggunakan kuesioner hardcopy serta google form guna memperluas jangkauan peneliti kepada responden. Total kuesioner dalam bentuk hardcopy yang disebarkan adalah sebanyak 73 kuesioner, dan yang kembali adalah 53 kuesioner. Sejumlah 6 responden mengisi melalui Google form. Dari total 59 data yang diperoleh, 8 di antaranya tidak dapat digunakan karena ketidaksesuaian kriteria partisipan dengan penelitian dalam hal diagnosis anak, sehingga total keseluruhan sampel yang dapat digunakan dalam penelitian ini adalah sebanyak 51 orang.

\section{Teknik Analisis}

Pengolahan data dalam penelitian ini menggunakan Statistical Package for Social Science (SPSS) versi 22. Peneliti terlebih dahulu melakukan uji normalitas dengan Kolmogorov-Smirnov. Hasil uji normalitas menunjukkan bahwa distribusi data adalah normal. Oleh karena itu, peneliti menggunakan metode korelasi Pearson Product Moment untuk menguji hubungan antara variabel resiliensi dan penerimaan orangtua. 


\section{ANALISIS DAN HASIL}

Responden yang berpartisipasi dalam penelitian ini berkisar pada usia 27 sampai dengan 58 dengan rata-rata partisipan berusia 42 tahun $(S D=7.1)$, dengan jumlah yang cukup seimbang antara responden yang berada pada rentang 21-40 tahun (43.2\%) dengan responden pada rentang usia 41-65 tahun (56.8\%). Sejumlah 34 responden memiliki anak laki-laki dengan ganguan ASD (66.7\%), dan 17 responden memiliki anak perempuan dengan gangguan ASD (33.3\%). Rata-rata anak yang terdiagnosis dengan gangguan ASD adalah 10 tahun $(S D=5.1)$ dengan rentang usia 2.5 sampai dengan 22 tahun.

Dari hasil korelasi, diperoleh nilai korelasi antara resiliensi dan penerimaan orangtua yang signifikan $(r=-.330, p<.05)$. Nilai negatif dari koefisien korelasi menunjukkan bahwa variabel resiliensi memiliki hubungan yang berbanding terbalik dengan skor alat ukur penerimaan orangtua. Hal ini dikarenakan alat ukur penerimaan orangtua berfokus pada perilaku penolakan. Nilai koefisien sebesar -.330 menunjukkan hubungan yang terdapat di antara kedua variabel adalah cukup.

Sedangkan dari hasil uji korelasi dimensi penerimaan orangtua dan resiliensi, diperoleh hasil bahwa terdapat dua dimensi yang berkorelasi secara signifikan dengan resiliensi, yakni dimensi hostile and aggressive $(r=-.300, p<.05)$ dan undifferentiated rejecting $(r=-.372, p<.05)$.

\section{DISKUSI}

Hasil analisis menunjukkan bahwa terdapat hubungan yang signifikan antara resiliensi dan penerimaan orangtua. Hubungan antara variabel resiliensi dan penerimaan orangtua dapat dijelaskan melalui beberapa hal. Salah satunya adalah faktor-faktor yang dapat mempengaruhi terbentuknya resiliensi. Faktor pertama yaitu kendali kognitif dan emosi individu, yaitu kemampuan individu untuk mengontrol perasaan yang tidak menyenangkan, tetap fokus meskipun dalam keadaan tertekan, serta dapat melihat tekanan sebagai suatu hal yang akan membuat individu semakin kuat (Connor \& Davidson, 2003).

Respon ibu terhadap anak yang terdiagnosis ASD dapat dilihat dalam interaksi sehari-hari antara ibu dan anak. Dengan bersikap tenang, respon individu dalam menghadapi anak yang terdiagnosis ASD tidak dipengaruhi oleh emosi semata, melainkan mampu melihat situasi sebagai kesempatan untuk berkembang menjadi individu yang lebih kuat. Emosi yang negatif membuat pikiran seseorang menjadi sempit, sehingga dapat memunculkan respon perilaku agresif atau justru menghindar (Fredrickson, 
2001). Dengan demikian, dalam kaitannya dengan mengurus anak yang terdiagnosis ASD, orangtua yang membiarkan dirinya dikuasai emosi negatif dapat berperilaku agresif terhadap anak atau justru menghindari dan mengabaikan anak.

Resiliensi memengaruhi bagaimana orangtua berinteraksi dengan anaknya, di mana orangtua dengan resiliensi yang rendah cenderung tidak peduli dengan kondisi anaknya, seperti menelantarkan anaknya atau menyerahkan tanggung jawab pengasuhan kepada orang lain (Cunningham \& Boyle, 2002). Dalam keadaan yang sulit sekalipun, orangtua yang resilien dapat beradaptasi dengan gangguan yang dimiliki anaknya dan menunjukkan perilaku penerimaan terhadap sang anak, yang merupakan hasil adaptasi yang positif. Hasil penelitian ini menunjukkan bahwa semakin tinggi resiliensi ibu, maka semakin rendah penolakan orangtua (dan semakin tinggi penerimaan orangtua). Semakin tinggi resiliensi ibu, maka ibu akan menghindari perilaku pengasuhan yang dingin, agresif, ataupun tidak mempedulikan anak. Ibu justru dapat menyesuaikan diri dan menunjukkan penerimaan kepada anaknya yang berkebutuhan khusus. Hal ini sejalan dengan apa yang disampaikan oleh Rutter (2006), di mana resiliensi menjadi salah satu faktor yang menentukan keberhasilan dan hasil adaptasi yang positif pada individu.

Salah satu manfaat resiliensi yaitu overcoming, yang membantu individu menghadapi dan mengatasi rintangan, serta membentuk masa depan yang ia inginkan (Reivich \& Shatte, 2002). Ibu yang resilien tidak menjadi pasrah dengan keadaan anaknya, namun berusaha memberikan yang terbaik bagi anaknya dengan memberikan pengasuhan yang dibutuhkan sang anak. Hasil ini sejalan pula dengan pendapat Browne, (2014) yang menyatakan bahwa orangtua yang mampu bangkit dalam situasi menekan dapat memberikan perhatian dan pengasuhan yang lebih positif kepada anak mereka, sehingga juga akan berdampak positif bagi perkembangan anak.

Begitu pula dengan manfaat resiliensi berupa bouncing back, di mana individu yang resilien dapat bangkit dari tekanan dan menjalin relasi yang baik dengan orang lain (Reivich \& Shatte, 2002), sehingga individu yang resilien tidak menolak anaknya, melainkan membangun relasi yang baik dengan anaknya yang memiliki gangguan ASD dalam bentuk perilaku pengasuhan yang hangat dan penuh kasih sayang. Resiliensi juga memiliki manfaat steering through, yaitu mampu mengatasi masalah tanpa bersikap negatif. Hal ini akan berdampak pada penerimaan orangtua yang termanifestasi dalam perilaku pengasuhan yang positif, dan bukannya menunjukkan perilaku pengasuhan yang negatif pada anak. 
Meskipun kesulitan terkait dengan mengasuh anak dengan gangguan ASD bersifat jangka panjang, ibu yang resilien akan mendapatkan manfaat berupa steeling effect, yaitu kapabilitas untuk mengurangi kerentanan individu terhadap stres, meskipun dipaparkan pada stressor dan kesulitan yang terus menerus (Lyons, dan kawan-kawan., 2009).

Penyesuaian diri juga merupakan salah satu faktor protektif yang ada pada resiliensi, yaitu adaptability (Reivich \& Shatte, 2002). Adaptability berbicara tentang karakteristik individu yang mampu beradaptasi dengan perubahan yang terjadi dalam hidupnya, dan menerima perubahan tersebut secara positif. Ibu yang menyesuaikan diri secara positif dengan kondisi gangguan ASD anaknya pada akhirnya juga semakin mengembangkan resiliensi yang ia miliki dalam dirinya. Menyesuaikan diri berarti ibu dapat menunjukkan perilaku pengasuhan yang adaptif sesuai dengan kebutuhan anak.

Ibu yang memiliki tingkat penerimaan yang lebih tinggi mampu melihat kondisi anak secara realistis, sehingga ibu juga dapat menyadari kelebihan dan kekurangan yang dimiliki anaknya (Dunst \& Trivette, 1986). Penerimaan yang realistis ini membuat ibu tidak terjebak dalam perasaan mengasihani dirinya sendiri, namun justru dapat bangkit dan melakukan berbagai tindakan yang bermanfaat bagi perkembangan anak. Penerimaan orangtua terhadap anak dapat membuat orangtua menjadi lebih sabar, mampu memahami perbedaan individu, serta mampu lebih berempati (Von Kluge \& Altiere, 2009). Dengan menghadapi masalah yang ada tanpa menghindar, ibu belajar menjadi sosok yang lebih resilien.

Orangtua yang menunjukkan penerimaan juga memiliki self-efficacy, yaitu keyakinan bahwa dirinya mampu mengatasi kesulitan terkait pengasuhan anaknya (Hurlock, 2014). Self-efficacy juga merupakan salah satu faktor protektif pada resiliensi (Connor \& Davidson, 2003). Hasil penelitian ini menunjukkan bahwa semakin tinggi penerimaan ibu, maka semakin tinggi pula resiliensi ibu. Ketika ibu memiliki tingkat penerimaan yang tinggi, ibu juga semakin mengembangkan resiliensi yang ia miliki dalam dirinya. Hal ini dikarenakan ibu merasa memiliki sumber daya dan kapabilitas yang dibutuhkan untuk mengasuh anaknya, sekaligus menghadapi tantangan dalam mengurus anak yang memiliki gangguan ASD. Keyakinan ibu untuk menjalani peran sebagai orangtua dari anak yang terdiagnosis ASD akhirnya membuat ibu tidak menyerah, namun justru bangkit kembali.

Jika dilihat lebih lanjut dalam kaitan antara dimensi penerimaan dengan resiliensi, dimensi hostile and aggressive dan undifferentiated rejecting memiliki hubungan yang signifikan dengan resiliensi, namun dimensi cold and unaffectionate dan dimensi indifferent and neglecting tidak. 
Resiliensi memampukan individu untuk bangkit kembali dan merespon masalah dengan emosi positif, serta menghindari dorongan yang muncul dari emosi negatif(Tugade \& Fredrickson, 2004), sehingga orangtua yang resilien dapat menghindari perilaku hostile and aggressive yang merupakan bentuk perilaku dari emosi negatif. Perilaku pengasuhan ibu yang hostile and aggressive bersumber dari dorongan atau impuls yang kurang terkendali, sedangkan salah satu faktor protektif dari resiliensi adalah kemampuan akan kendali diri. Sehingga perilaku hostile and aggressive yang dimiliki ibu berkorelasi negatif dengan resiliensi.

Perilaku orangtua yang memenuhi kebutuhan anaknya dan memberikan pengasuhan secara rutin tidak dapat langsung diartikan sebagai perilaku penerimaan orangtua terhadap anak (Rohner, 1986). Hal ini dapat menjelaskan mengapa tidak ada hubungan yang signifikan antara dimensi cold and unaffectionate dan dimensi indifferent and neglecting. Dimensi cold and unaffectionate merupakan bentuk penolakan yang tidak menunjukkan kehangatan dan afeksi pada anak, sedangkan indifferent and neglecting merupakan bentuk penolakan yang mengabaikan atau tidak mempedulikan anak.

Terutama dalam kaitannya dengan budaya dan nilai religiusitas masyarakat Indonesia, terdapat pandangan bahwa orangtua memiliki tanggung jawab untuk membesarkan anak, termasuk apabila anak tersebut memiliki kebutuhan khusus. Rasa tanggung jawab itulah yang mendorong orangtua untuk berperilaku tertentu, terlepas dari tingkat resiliensi yang mereka miliki. Dalam komunikasi personal peneliti dengan beberapa responden, ibu dari anak yang terdiagnosis ASD mengatakan bahwa bagaimanapun kondisi anak, anak merupakan anugerah dari Tuhan yang menjadi tanggung jawab orangtua. Oleh karena itu para ibu mengatakan bahwa mereka tetap menyayangi anak mereka. Hal ini sesuai dengan pernyataan Hurlock (2014), bahwa nilai budaya mengenai cara terbaik mengasuh anak akan mempengaruhi sikap orangtua dan cara mereka memperlakukan anaknya.

Sementara itu, dimensi undifferentiated rejecting mengacu pada kondisi di mana orangtua menunjukkan penolakan terhadap anak, namun bentuk penolakan tersebut tidak dapat dikategorikan apakah unaffectionate, aggressive, atau neglecting. Pada dimensi undifferentiated rejecting, tidak ada indikator perilaku penolakan yang objektif (Rohner, 1986). Dapat diartikan bahwa penolakan undifferentiated rejecting menggambarkan pengasuhan yang tidak sepenuhnya penuh kasih sayang terhadap anak, namun juga tidak sepenuhnya agresif ataupun mengabaikan anak. Berkaitan pula dengan nilai budaya dan religiusitas yang telah dijelaskan sebelumnya, ibu dapat saja merasakan perasaan menolak terhadap anaknya, namun tidak terlihat bentuk nyatanya dalam perilaku ibu terhadap sang anak. Oleh karena itu, dimensi undifferentiated rejecting-lah yang memiliki hubungan signifikan 
dengan resiliensi, dan bukannya dimensi cold and unaffectionate ataupun indifferent and neglecting.

Selain faktor-faktor yang dianalisis berdasarkan hasil pengambilan data dan keterkaitannya dengan teori, peneliti juga mengidentifikasi adanya kemungkinan bahwa beberapa partisipan melakukan social desirability response. Social desirability response merupakan salah satu isu yang paling sering ditemui ketika seseorang mengisi kuesioner dalam bentuk self-report, terutama apabila topik yang dibahas menyangkut isu-isu yang sensitif secara sosial (Van de Mortel, 2008). Peneliti sudah berupaya untuk menekankan confidentiality dengan tidak menyediakan kolom nama responden, serta memberikan amplop sebagai tempat untuk responden dapat menyimpan kuesionernya yang telah diisi. Namun, memiliki anak dengan gangguan ASD dapat menjadi isu yang sensitif untuk dibicarakan dengan orang lain, apalagi dengan orang yang baru dikenal. Hal ini dapat membuat partisipan tidak menjawab berdasarkan keadaan diri yang sebenarnya, melainkan memberikan respons sesuai dengan kondisi ideal yang mereka inginkan, sehingga kecenderungan social desirability response berpotensi menjadi keterbatasan penelitian ini. Keterbatasan lain dalam penelitian ini adalah ukuran sampel dalam penelitian yang tidak besar, sehingga diperlukan kehati-hatian dalam menginterpretasi dan menggeneralisasi hasil penelitian ini.

\section{SIMPULAN DAN SARAN}

\section{Simpulan}

Tujuan penelitian ini adalah untuk menguji secara empiris hubungan antara resiliensi dan penerimaan orangtua pada ibu dari anak yang terdiagnosis Autism Spectrum Disorder (ASD). Dari hasil pengolahan statistik yang dilakukan, diperoleh hasil yang sesuai dengan hipotesis peneliti, yaitu terdapat korelasi signifikan antara resiliensi dan penerimaan orangtua. Nilai korelasi bermakna bahwa terdapat hubungan yang cukup, sehingga dapat dikatakan orangtua yang memiliki resiliensi dapat lebih menerima anaknya yang terdiagnosis ASD. Sedangkan dari hasil uji korelasi dimensi penerimaan orangtua dan resiliensi, diperoleh dua dimensi yang berkorelasi secara signifikan dengsan resiliensi, yakni dimensi hostile and aggressive dan undifferentiated rejecting.

\section{Saran Teoretis}

Diharapkan adanya replikasi penelitian ini dengan perbaikan pada beberapa hal. Pertama, jumlah sampel perlu diperbanyak agar hasil penelitian dapat digeneralisasi secara lebih luas dan dibandingkan 
secara merata. Kedua, penelitian selanjutnya dapat menggabungkan antara metode kuantitatif dan kualitatif sebagai cara untuk pengambilan data dari responden. Ketiga, dapat dilakukan analisis statistik lebih lanjut terhadap skor dari alat ukur penerimaan orangtua dengan menggunakan nilai tengah pada masing-masing dimensi penerimaan, di mana skor yang berada di atas nilai tengah dikategorikan sebagai penerimaan rendah, sedangkan skor yang berada di bawah nilai tengah dikategorikan sebagai penerimaan tinggi. Namun hal ini hanya dapat dilakukan jika terdapat jumlah partisipan yang besar, sehingga pembagian jumlah anggota dalam setiap kelompok merata. Dapat pula mempertimbangkan untuk menggunakan teori atau konstruk lain yang spesifik untuk sampel ibu dari anak yang terdiagnosis ASD. Peneliti selanjutnya juga disarankan untuk menekankan mengenai anonimitas dan confidentiality pada responden agar responden bersedia mengisi kuesioner sesuai dengan keadaan diri yang sebenarnya. Terakhir, diperlukan penelitian lanjutan berupa uji pengaruh antara variabel resiliensi dan penerimaan orangtua, guna mengetahui lebih jelas arah pengaruh kedua variabel tersebut. Dengan demikian, hasil penelitian dapat bermanfaat untuk menentukan intervensi yang tepat dan lebih spesifik.

\section{Saran Praktis}

Praktisi di bidang kesehatan mental, seperti konselor dan psikolog, dapat mengadakan psikoedukasi dalam bentuk seminar dan penyuluhan mengenai ASD supaya para ibu dan masyarakat awam memiliki pemahaman yang lebih mendalam mengenai ASD itu sendiri. Dengan memiliki pemahaman yang lebih, ibu dapat semakin mengerti kelebihan dan kekurangan anak, sehingga dapat lebih menunjukkan penerimaan pada anak. Dapat pula dilakukan intervensi yang berfokus pada peningkatan resiliensi atau penerimaan orangtua terhadap anak, guna memampukan orangtua menghadapi kesulitan yang dialami dalam kehidupan sehari-hari dan mencapai perkembangan anak yang lebih maksimal.

Bagi orangtua, terutama ibu yang memiliki anak dengan gangguan ASD, dapat menambah wawasan mengenai strategi yang baik untuk bangkit dari keadaan yang menekan, serta meningkatkan penerimaan terhadap anak dengan bergabung dalam komunitas-komunitas orangtua yang juga memiliki tantangan yang sama, sehingga dapat saling bertukar informasi dan memberikan dukungan. Hal ini juga perlu dilakukan baik oleh ibu yang bekerja maupun ibu yang sudah memiliki pihak lain yang membantu dalam mengurus anak, agar semakin mengenal anak secara pribadi melalui interaksi yang berkualitas dengan anak. 
Sedini mungkin, sebaiknya ibu mempersiapkan anaknya yang terdiagnosis dengan ASD untuk dapat mandiri, terutama dalam melakukan aktivitas bina diri sehari-hari, sehingga kelak anak dapat mengurus dirinya sendiri pada saat ia sudah memasuki usia dewasa. Persiapan ini juga perlu dibantu oleh sekolah, dengan mengadakan program-program kemandirian anak. Selain itu, guru dan pihak sekolah perlu lebih intensif dalam berkomunikasi dengan orangtua dari anak yang terdiagnosis ASD. Selain memberikan laporan perkembangan anak, sekolah dapat mengadakan pertemuan rutin dengan orangtua. Sekolah dapat mencari tahu sejauh mana penerimaan orangtua terhadap anak, serta memberikan pemahaman untuk membantu meningkatkan penerimaan orangtua.

Lembaga-lembaga pemerintahan dan swasta terkait dapat menyediakan komunitas dan support system, di mana para ibu dari anak yang terdiagnosis ASD dapat saling berdiskusi secara terbuka, guna meningkatkan resiliensi dan penerimaan orangtua. Pemerintah juga dapat memberikan bantuan dana untuk Sekolah Luar Biasa atau sekolah inklusi, untuk mempermudah akses pendidikan anak-anak dengan gangguan ASD, sehingga juga meringkankan beban orangtua.

\section{REFERENSI}

American Psychiatric Association. (2013). Diagnostic and statistical manual of mental disorders (5th ed.). Washington, DC: American Psychiatric Publishing.

Autism Europe (Ed). (2001). Autism and family needs. Ditemu kembali dari http://www. autismeurope. org/files/files/familyneeds-eng2.pdf

Barnett, D., Clements, M., Kaplan-Estrin, M., \& Fialka, J. (2003). Building new dreams supporting parents' adaptation to their child with special needs. Infants and Young Children, 16(3), 184-200.

Browne, C. H. (2014). The strengthening families approach and protective factors framework: Branching out and reaching deeper. Ditemu kembali dari http://www.cssp.org/reform/ strengtheningfamilies/2014/The-Strengthening-Families-Approach-and-Protective-FactorsFramework_Branching-Out-and-Reaching-Deeper.pdf

Connor, K. M., \& Davidson, J. R. T. (2003). Development of a new resilience scale: The conor-davidson resilience scale (CD-RISC). Depression and Anxiety, 18, 76-82. 
Cunningham, C. E., \& Boyle, M. H. (2002). Preschoolers at risk for attention deficit hyperactivity disorder and oppositional deviant disorder: Family, parenting, and behavioral correlates. Journal of Abnormal Child Psychology, 30, 555-569.

Danuatmaja, B. (2003). Terapi anak autis di rumah. Jakarta, Indonesia: Puspaswara.

Dunst, C. J., \& Trivette, C. M. (1986). Looking beyond the parent-child dyad for the determinants of interaction. Infant Mental Health Journal, 7, 69-80.

Fredrickson, B. L. (2001). The role of positive emotions in positive psychology: The broaden-and-build theory of positive emotions. American Psychologist: Special Issue, 56, 218-226.

Greeff, A. P., \& van der Walt, K. (2010). Resilience in families with an autistic child. Education and Training in Autism and Developmental Disabilities, 45(3), 347-355.

Herrman, H., Stewart, D. E., Diaz-Granados, N., Berger, E. L., Jackson, B., \& Yuen, T. (2011). What is resilience? Canadian Journal of Psychiatry, 56(5), 258-265.

Hurlock, E. B. (2014). Perkembangan anak jilid 2. Jakarta, Indonesia: Erlangga.

Kandel, I., \& Merrick, J. (2007). The child with a disability: Parental acceptance, management and coping. The Scientific World Journal, 7, 1799-1809. doi: 10.1100/tsw.2007.265

Kurnia, E. (2015, April 2). Autisme di Indonesia terus meningkat. Ditemu kembali dari http://lifestyle. okezone.com/read/2015/04/02/481/1128312/autisme-di-indonesia-terus-meningkat

Llyod, T. J., \& Hastings, R. (2009). Hope as psychological resilience factor in mothers and fathers of children with intellectual disabilites. Journal of Intellectual Disability Research, 5(2), 160-166.

Lyons, D. M., Parker, K. J., Katz, M., \& Schatzberg, A. F. (2009). Developmental cascades linking stress inoculation, arousal regulation, and resilience. Frontiers in Behavioral Neuroscience, 3, 32.

Mandell, D. S. (2012). Understanding and addressing the impact of autism on the family. Leonard Davis Institute of Health Economics Issue Brief, 17, 1-4. Ditemu kembali dari http://dihealtheconomist. com/media/understanding_and_addressing_the_impact_of_autism_on_the_family.pdf.

Mash, E. J., \& Wolfe, D. A. (2013). Abnormal child psychology (5th ed.). Belmont, CA: Thomson Wadsworth.

Masten, A. S. (2001). Ordinary magic: Resilience processes in development. American Psychologist, $56(3), 227-238$. 
Papageorgiou, V., \& Kalyva, E. (2010). Self-reported needs and expectations of parents of children with autism spectrum disorders who participate in support groups. Research in Autism Spectrum Disorders, 4(4), 653-660.

Puteri, M. (2014). Pengaruh spiritualitas terhadap resiliensi pada orangtua dari anak berkebutuhan khusus (Skripsi tidak dipublikasikan). Universitas Pelita Harapan, Indonesia.

Rathore, S., \& Mathur, R. (2014). Resilience and happiness: Source of coping in mothers with mentally retarded children. Indian Journal of Positive Psychology, 5(4), 451-455.

Reivich, K., \& Shatte, A. (2002). The resilience factor: 7 essential skills for overcoming life's inevitable obstacles. New York, NY: Broadway Books.

Rohner, R. P. (1986). Handbook for the study of parental acceptance and rejection (Rev. ed.). Storrs, CT: Center for the Study of Parental Acceptance and Rejection, University of Connecticut.

Rohner, R. P. (2005). Parental Acceptance-Rejection Questionnaire (PARQ): Test manual. In R. P. Rohner \& A. Khaleque (Eds.), Handbook for the study of parental acceptance and rejection (4th ed., pp. 43-106). Storrs, CT: Rohner Research Publications.

Rutter, M. (2006). Implications of resilience concepts for scientific under-standing. Annals of the New York Academy of Sciences, 1094, 1-12.

Safaria, T. (2005). Autisme pemahaman baru untuk hidup bermakna bagi orangtua. Yogyakarta, Indonesia: Graha Ilmu.

Smith, B. W., Dallen, J., Wiggins, K., Tooley, E., Christopher, P., \& Bernard, J. (2008). The brief resilience scale: Assessing the ability to bounce back. International Journal of Behavioral Medicines, 15, 194-200.

Taylor, S. E. (2012). Health psychology (8th ed). New York, NY: McGraw-Hill.

Tugade, M., \& Fredrickson, B. L. (2004). Resilient individuals use positive emotions to bounce back from negative emotional experiences. Journal of Personality and Social Psychology, 86(2), 320-333. doi: 10.1037/0022-3514.86.2.320

Van de Mortel, T. F. (2008). Faking it: Social desirability response bias in self-report research. Australian Journal of Advanced Nursing, 25(4), 40-48. 
Von Kluge, S. \& Altiere, M. (2009). Searching for acceptance: Challenges encountered while rising a child with autism. Journal of Intellectual and Developmental Disability, 34(2), 142-152.

Walsh, F. (2003) Family resilience: A framework for clinical practice. Family Process, 42(1), 1-18.

Wolkow, K. E. \& Ferguson, H. B. (2001), Community factors in the development of resiliency: Considerations and future directions. Community Mental Health Journal, 37(6), 489-498. 